"Si va hablando solo por la calle: trabaja en Dálmine". La salud obrera como campo de disputa en una gran empresa siderúrgica: entre la resistencia de los trabajadores y las prácticas de violencia estatal y empresarial (1974-1978)

Pablo Javier Peláez

páginas / año $12-\mathrm{n}^{\circ} 28$ Enero-Abtil / ISSN 1851-992X/ 2020

http://revistapaginas.unr.edu.ar/index.php/RevPaginas

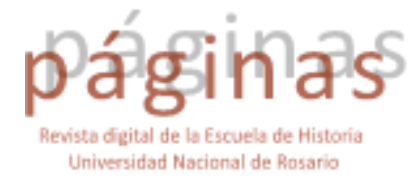

\title{
"Si va hablando solo por la calle: trabaja en Dálmine". La salud obrera como campo de disputa en una gran empresa siderúrgica: entre la resistencia de los trabajadores y las prácticas de violencia estatal y empresarial (1974-1978)
}

\author{
"Si va hablando solo por la calle: trabaja en Dálmine". \\ Worker's health as a field of conflict in a steel factory: between \\ worker's resistance and state and business violence practices
} (1974-1978)

\author{
Pablo Javier Peláez \\ Instituto de Investigaciones Sociales de América Latina; \\ Concejo Nacional de Investigaciones Científicas y Técnicas (Argentina)*
}

\begin{abstract}
Resumen
El artículo propone analizar un conflicto laboral suscitado entre 1974 y 1978 en una de las empresas con mayor cantidad de víctimas trabajadoras y sindicalistas durante el terrorismo de estado: la siderúrgica Dálmine-Siderca, ubicada en Campana y perteneciente al grupo Techint. La disputa tuvo como eje las condiciones de insalubridad laboral, en un contexto determinado por la ampliación de la planta industrial y la represión extrema sufrida por el colectivo obrero de la fábrica.

La reconstrucción del entramado conflictivo nos permite realizar un primer avance en un campo de estudios poco desarrollado en la historiografía, relativo a las disputas específicas por la salud y las condiciones de trabajo en las fábricas, y encontrar líneas explicativas que contribuyan a identificar algunas de las razones de aquella represión particularmente intensa.

El trabajo consta de cuatro apartados, en los que se desarrollan un breve estado de la cuestión sobre la temática, un recorrido por las condiciones de trabajo en la acería de la planta, una aproximación empírica al conflicto y la dinámica represiva, y algunas reflexiones
\end{abstract}

\footnotetext{
* El presente trabajo forma parte de mi investigación de Doctorado en Historia (FFyL, UBA) titulada "Cambio tecnológico, estrategias empresariales y experiencia de lucha y organización obrera: el caso de la empresa Dálmine-Siderca (Campana, 1974-1989)”, y dirigida por Victoria Basualdo. Integro el PICT "Transformaciones estructurales y relaciones laborales: cambios productivos y estrategias sindicales en la industria siderúrgica y azucarera desde mediados de los años 70 hasta la actualidad", dirigido por Victoria Basualdo. Agradezco especialmente a Victoria Basualdo, Andrea Copani, Alejandra Esponda, Silvia Nassif y Julia Strada (miembros del Programa de Estudios del Trabajo, Movimiento Sindical y Organización Industrial del Área de Economía y Tecnología de FLACSO), así como a Alejandro Jasinski y Federico Vocos, por los comentarios realizados a una versión preliminar de este artículo.

Esta obra está sujeta a la Licencia Reconocimiento-NoComercial-CompartirIgual 4.0 Internacional de Creative Commons. http://creativecommons.org/licenses/by-nc-sa/4.0/

(cc) BY-NC-SA
} 


\title{
Pablo Javier Peláez
}

generales. Utilizamos una amplia variedad de fuentes: balances y publicaciones empresarias, expedientes del Ministerio de Trabajo, legajos de inteligencia, prensa local y testimonios de ex trabajadores.

Palabras clave

Salud Obrera; Violencia empresarial; Sindicatos; Terrorismo de Estado; Siderurgia

\begin{abstract}
The article aims to analyze a labor conflict raised between 1974 and 1978 in one of the firms with the highest number of workers and union victims during the state terrorism: the steel industry Dálmine-Siderca, located in Campana and belonging to the Techint Group. The dispute focused on the unhealthy labour conditions, in a context determined by the expansion of the industrial plant and the extreme repression suffered by the worker's collective.

The reconstruction of the conflictive framework allows us to make a first advance in a field that was little developed in historiography, related to specific disputes for health and working conditions in factories, and find explanatory lines that help us identify some of the reasons for that particularly intense repression.

The work has been structured in four sections. The first one developes a brief state of the issue on the subject. The following describes the working conditions in the steelworks of the industrial plant. After that, we empirically approach the conflict and repressive dynamics. And finally, we draw some general reflections.

We use a wide variety of primary sources: company's balance and business publications, files of the Ministry of Labor, intelligence files, local press and testimonies of former workers.
\end{abstract}

\section{Keywords}

Worker's health; Business violence; Unions; State Terrorism; Steel industry

En este trabajo nos proponemos analizar un conflicto laboral suscitado entre 1974 y 1978 en una de las empresas con mayor cantidad de víctimas trabajadoras y sindicalistas durante el terrorismo de estado: la siderúrgica Dálmine-Siderca, ubicada en Campana y perteneciente al grupo Techint. La disputa tuvo como eje las condiciones de insalubridad y se desarrolló a lo largo de estos cuatro años, en un contexto determinado por la profunda ampliación de la planta industrial y la represión extrema sufrida por el colectivo obrero.

La reconstrucción de este entramado conflictivo nos permite realizar un primer avance en un campo de estudios poco desarrollado en la historiografía de la clase trabajadora en Argentina, relativo a las disputas específicas por la salud y las condiciones de trabajo en las fábricas, y encontrar líneas explicativas que contribuyan a identificar algunas de las razones de la represión particularmente intensa. Con la idea de que los conflictos en torno a la salud laboral tuvieron una importancia cualitativa para explicar la álgida conflictividad social del período analizado, discutiremos algunas de las interpretaciones vigentes.

Este trabajo parte de la reconstrucción minuciosa del caso, analizando indicios tanto de los discursos como de las acciones que llevaron adelante los trabajadores y la empresa en dos fases, evidenciando que las prácticas de violencia empresarial 
"Si va hablando solo por la calle: trabaja en Dálmine". La salud obrera como campo de disputa en una gran empresa siderúrgica: entre la resistencia de los trabajadores y las prácticas de violencia estatal y empresarial (1974-1978)

cumplieron un rol central para la resolución provisoria de la disputa en favor de la dirección empresarial.

En primer lugar, desarrollamos un breve estado de la cuestión sobre la temática. En segunda instancia, realizamos un recorrido empírico con el despliegue de diversas fuentes primarias sobre el caso particular. Por último, presentamos algunas reflexiones generales y una hipótesis de trabajo a futuro.

\section{La conflictividad por la salud en las fábricas entre 1973 y la última dictadura: un breve estado de la cuestión}

Ya desde principios de los años 70, en el devenir mismo de los hechos, algunos análisis resaltaron la importancia de los reclamos obreros sobre salubridad y seguridad laboral, inmersos en una disputa más general por el control de las condiciones de trabajo y el cuestionamiento a los líderes sindicales desde las bases (Pasado y Presente, 1973). Retomando esa línea, años más tarde Jelin (1977) evidenció que el eje de conflictividad centrado en el control de las condiciones de trabajo y la salud laboral tuvo una importancia cualitativa para el período específico entre mayo de 1973 y mediados de 1974, en un particular clima político que posibilitaba ese tipo de demandas, en relación con un alto grado de movilización de las bases y un creciente cuestionamiento a los liderazgos sindicales; y a partir de la vigencia sólida del Pacto Social, el cual no permitía la discusión salarial directa.

La autora también señaló, sin embargo, que la protesta en este eje retrocedió en la coyuntura abierta por la muerte de Perón en julio de 1974, con el resquebrajamiento del Pacto Social y el avance más decidido desde las cúpulas sindicales y el Ministerio de Trabajo por disciplinar a sectores de oposición gremial, desmovilizar a las bases y centralizar la estructura sindical. Hacia fines de 1974, resaltó la emergencia del ausentismo laboral como forma de expresión del descontento obrero desde el lugar de trabajo, lo cual pudo relacionarse tanto con la aplicación de la legislación represiva a las manifestaciones colectivas de protesta como con la estabilidad laboral que aseguraba la recientemente sancionada Ley de Contrato de Trabajo.

Estudios posteriores sobre la conflictividad obrera general del período 1973-1976 no le otorgaron un peso específico al eje de salubridad (Pegoraro, 1979; Izaguirre, 2009; Löbbe, 2006), aunque en algunos casos apareció mencionado en forma subordinada a otras variables como los posicionamientos de las dirigencias sindicales (Schneider, 2017; Torre, 1983), las estrategias de las corrientes obreras de izquierda (Werner \& Aguirre, 2009) o la política laboral del tercer peronismo (Schneider, 2015). Algunos de estos trabajos, sin embargo, retomaron parte de la tesis de Jelin, encorsetando este tipo de conflictividad a la coyuntura de 1973-1974 y asociándola puntualmente a la vigencia del Pacto Social. Particularmente Schneider (2017) afirmó que los reclamos por condiciones laborales y de salud en realidad encubrieron demandas que, indirectamente y en última instancia, 


\section{Pablo Javier Peláez}

buscaban las mejoras salariales que venían siendo frenadas por el Pacto Social. En sentido similar, Torre había planteado que, en la imposibilidad de negociar mejores ingresos, los trabajadores intentaron obtenerlos en forma indirecta, reclamando por la reclasificación de tareas consideradas insalubres, por las que se esperaba un aumento en las retribuciones (Torre, 1983).

En un trabajo reciente, Lissandrello (2017) retomó la conflictividad por salubridad, seguridad e higiene laboral durante 1973-1974 relacionándola a la específica estrategia de inserción sindical de Montoneros-Juventud Trabajadora Peronista y el accionar del Instituto de Medicina del Trabajo, perteneciente a la UBA. Su tesis central fue que la lucha por condiciones laborales y trabajo salubre estuvo vinculada a la búsqueda de Montoneros por articular una construcción sindical que pudiera disputar con las burocracias sindicales por dentro del movimiento peronista, sin enfrentar al Pacto Social y al propio Perón. Lissandrello destacó la coincidencia entre aquella estrategia y el planteo programático y práctico del Instituto, que se vio plasmado en la intervención conjunta en diferentes conflictos gremiales.

Desde una mirada distinta, Basualdo y Lorenz (2012) advirtieron la necesidad de profundizar en la historia de los trabajadores industriales durante la segunda etapa de industrialización por sustitución de importaciones (ISI), en relación a aspectos vinculados con la organización de la producción, las condiciones de trabajo y la salubridad e higiene en las fábricas. Se abrió en esta perspectiva un interés más amplio por este eje de disputa, intentando conjugar la atención sobre variables objetivas, relacionadas al proceso de trabajo en industrias dinámicas, con cuestiones subjetivas, ligadas a la organización y las luchas de la clase trabajadora. Tanto en los casos de Acindar Villa Constitución y Alpargatas Barracas (Basualdo, 2011, 2018) como en el de Astilleros Astarsa (Lorenz, 2007, 2013) las demandas por accidentes de trabajo, condiciones insalubres e insuficiente atención médica actuaron como disparadores para la organización de agrupaciones combativas hacia principios de los años setenta. En una línea similar, Soul (2014) verificó en la empresa siderúrgica estatal SOMISA que las demandas por el reconocimiento de la insalubridad de sectores y por la aplicación de regímenes de trabajo especiales generaron procesos de movilización gremial en 1966/67, 1973 y 1982/83, los cuales se constituyeron en instancias de importancia para la conformación de colectivos reivindicativos en la fábrica y para la definición de específicas estrategias sindicales. Otros estudios de caso enfocados en establecimientos de ramas dinámicas del período como la automotriz, la naval y la metalúrgica, mostraron, en sintonía, a la salud laboral como eje de conflicto central y/o puntapié para la organización obrera en el espacio productivo desde principios de los años setenta (Schmucler, Gordillo \& Malecki, 2009; Barragán, 2015; Ríos, 2017).

Respecto a la última dictadura, los primeros estudios realizados durante los años 80 y 90 evidenciaron los impactos generales que la dictadura produjo sobre el mercado de trabajo, la legislación laboral y la estructura de la clase obrera, así como las formas en que los trabajadores de base y las dirigencias sindicales respondieron (o no) a esa ofensiva (Gallitelli y Thompson, 1982; Delich, 1982, 1983; Bieber, 1983; 


\section{"Si va hablando solo por la calle: trabaja en Dálmine". La salud obrera como campo de disputa en una gran empresa siderúrgica: entre la resistencia de los trabajadores y las prácticas de violencia estatal y empresarial (1974-1978)}

Abós, 1983; Fernández, 1985; Pozzi, 1988; Falcón, 1996). Desde comienzos de la década del 2000 se desarrollaron distintas investigaciones que, partiendo de estudios de caso o regionales, dialogaron con algunas de esas apreciaciones iniciales más generales. Muchos de estos trabajos presentaron novedosas preguntas, problemáticas y tópicos, a partir del análisis de archivos y repositorios documentales abiertos en los últimos años. ${ }^{1}$ En términos generales, estos aportes recientes evidenciaron que el accionar de la clase trabajadora, inserto en un proceso de cambios estructurales fuertemente regresivos, tuvo una primera etapa en la que predominaron formas de resistencia "molecular" y "subterránea" desde los espacios de trabajo, y una segunda etapa, iniciada con la Jornada Nacional de Protesta de abril de 1979, en la que se evidenció una reemergencia de las formas de lucha tradicionales, más abiertas y visibles, aún en un contexto de desarticulación y represión de la actividad sindical (Basualdo, 2010).

Si bien existieron algunas menciones puntuales a la cuestión de la salud en los análisis más globales de la conflictividad del período (Abós, 1984; Fernández, 1985; Pozzi, 1988), incluso los trabajos que la tomaron como variable a atender dentro de la disputa a nivel de los espacios de trabajo no la han abordado como eje central o como problemática a desarrollar en su especificidad. ${ }^{2}$

En suma, vemos que más allá del considerable desarrollo de los estudios sobre conflictos laborales en el período que consideramos en este trabajo, aquellos motivados por condiciones laborales y de salud fueron un terreno escasamente explorado en su especificidad por la historiografía especializada.

En pos de realizar un avance en ese sentido, entendemos que es necesario remarcar sintéticamente algunas consideraciones de índole teórica.

En un clásico texto, Hyman (1981) definió al campo de las relaciones industriales como aquel que estudia los procesos de control sobre las relaciones de trabajo; y observó la centralidad que adopta la incesante disputa por el poder entre el capital y el trabajo en el espacio laboral, relacionándolo a la capacidad de cada uno de los polos de la contradicción por controlar su medio ambiente físico y social, y por la posibilidad de influir sobre las decisiones tomadas (o no) por el otro. En un mismo

\footnotetext{
1 Se pueden ver, entre otros, los trabajos de Basualdo (2010, 2011), Barragán (2016), Carminatti (2010), Dicósimo (2016), Ghigliani (2012), Lorenz (2007, 2013), Simonassi (2007), Zorzoli (2016, 2018), así como el informe de Responsabilidad Empresarial en delitos de lesa humanidad (AEyT FLACSO, CELS, PVyJ, \& SDH, 2016). Para un estado del arte exhaustivo sobre el estudio de trabajadores y dictadura en la Argentina, ver Venero (2015) y Basualdo (2018).

2 Nos referimos al caso de SEGBA (Ghigliani, 2012); a los de Metalúrgica Tandil y Loma Negra (Dicósimo, 2016); al de SOMISA (Soul, 2014) y a los de Ingenio Concepción, Acindar, Dálmine, Astilleros Astarsa y Mestrina, Lozadur, Cattáneo, Ford, Mercedes Benz, Grafa, Grafanor, Propulsora Siderúrgica, Petroquímica Sudamericana, Alpargatas, Molinos Río de la Plata, Fiat y Loma Negra (AEyT FLACSO et al., 2016). Si bien desde una mirada antropológica y referida al proceso de reconversión productiva de los años 90, destacamos el trabajo de Esponda (2012), quien para el caso de Propulsora Siderúrgica en Ensenada, problematizó específicamente la cuestión de la salud desde la perspectiva de los trabajadores.
} 
sentido, Adolfo Gilly $(1985,1986)$ se refirió a la existencia de una "guerra de posiciones" por el control del proceso productivo, en lo que consideró como el núcleo de la dominación celular del capital: la fábrica.

Retomando esa perspectiva, entendemos que dentro de la dinámica de producción fabril el capital y los trabajadores ponen en juego una serie de tácticas para definir qué trabajo se hace y cómo se hace. Distintas prácticas son llevadas por los operarios en forma organizada y desorganizada, individual y colectiva; mientras que el capital despliega una serie de estrategias que van desde formas paternalistas y de "despotismo hegemónico" (Burawoy, 2014) hasta formas abiertas de disciplinamiento (De Gaudemar, 1991) y violencia (Jasinski, 2019). Bajo la idea de "frontera de control" distintos autores evidenciaron aquel nivel de disputa por quién y cómo determina la cantidad y calidad de trabajo realizado en cada espacio productivo, definido por el choque entre esas estrategias patronales y las formas de "control obrero" de la producción desplegadas por los trabajadores ${ }^{3}$, en un marco histórico específico y en articulación con distintas formas de intervención estatal en el lugar de trabajo (Darlington, 2014; Edwards, 1986; Hyman, 1981). La "frontera de control" representa un compromiso insatisfactorio para las partes, redefinido continuamente en un proceso de presión y reacción, de lucha abierta y tácita.

En este trabajo particular indagaremos en la disputa por la salud obrera como elemento central para comprender los movimientos de aquella "frontera de control" y de las relaciones industriales en la planta de producción, en un período histórico en el que entendemos que esta se constituyó como una variable clave dentro de la conflictividad social más general. Como hemos planteado en abordajes previos (Peláez, 2017), la profundización de las demandas en relación a la salud obrera se dio en el contexto de la crisis capitalista desatada desde fines de la década del sesenta, que estuvo caracterizada, entre otros aspectos, por la radicalización de la disputa entre el capital y el trabajo desde los espacios de producción, y por el creciente peso de las reivindicaciones obreras de base centradas en el control de las condiciones de producción y en el cuestionamiento a la división del trabajo capitalista (Antunes, 2013). Con temporalidades y desarrollos particulares, este proceso general se manifestó en diferentes partes del mundo, constituyendo una de las experiencias paradigmáticas la de los obreros automotrices de la Fiat Mirafiori en Italia, que dieron origen al denominado "modelo obrero". Este modelo, difundido en 1969 como resultado de un trabajo conjunto entre obreros y técnicos profesionales desde una de las secciones de la fábrica automotriz, llegó a representar una de las propuestas más acabadas para el estudio de las condiciones de trabajo y la construcción de una plataforma de demandas, prácticas y estrategias para la defensa de la salud obrera y el avance en el control de las condiciones laborales por los propios trabajadores desde sus espacios laborales (Laurell, 1975).

\footnotetext{
${ }^{3}$ Entendemos a las prácticas de "control obrero" como la supervisión y hasta la obstrucción que pueden ejercer los trabajadores sobre las decisiones tomadas por una dirección empresarial que sigue reteniendo la soberanía final (Hyman, 1978).
} 
"Si va hablando solo por la calle: trabaja en Dálmine". La salud obrera como campo de disputa en una gran empresa siderúrgica: entre la resistencia de los trabajadores y las prácticas de violencia estatal y empresarial (1974-1978)

Partiendo de un balance de aquella experiencia, la reconocida teórica de la medicina social latinoamericana Asa Cristina Laurell definió una fructífera vía de entrada para entender el proceso de salud-enfermedad obrera en su carácter histórico-social y a partir de sus múltiples determinaciones. Puntualmente, Laurell destacó que la presencia e intensidad de determinadas cargas laborales (físicas, químicas, biológicas, mecánicas, psíquicas y fisiológicas) ${ }^{4}$ y patrones de desgaste del cuerpo obrero en el espacio fabril ${ }^{5}$ son definidos históricamente por una articulación dinámica entre factores de índole objetiva, relacionados al proceso de valorización del capital y al proceso de trabajo, y factores de carácter subjetivo, vinculados a la dinámica de conflicto entre el capital y el trabajo por el control de las condiciones de producción (Laurell, 1982; Laurell \& Noriega, 1989).

\section{Un recorrido por las condiciones laborales en la acería de Dálmine-Siderca en la segunda ISI}

La planta de tubos Dálmine Safta fue inaugurada en Campana en 1954, bajo el mando del grupo empresario Techint S.A.I.C., fundado nueve años antes por el italiano Agostino Rocca. La fábrica se especializó desde el principio en la producción de tubos de acero sin costura, utilizados principalmente para la perforación, entubado y extracción de pozos petrolíferos; siendo la única productora de esta vital mercancía en el país y abasteciendo centralmente la demanda de la empresa estatal YPF. Hacia 1963 comenzó a funcionar, anexa a la fábrica de tubos, la planta de acería, pasando la empresa a denominarse Dálmine-Siderca por la integración de ambas. ${ }^{6}$ La producción de acero resultó también fundamental en un rubro clave para el desarrollo de la segunda etapa de la ISI, en el que el país había sido históricamente deficitario (Azpiazu, Basualdo, \& Kulfas, 2005).

Luego de diversas expansiones realizadas durante la década del sesenta, hacia marzo de 1974 la asamblea de accionistas decidió ejecutar el más ambicioso plan de ampliación de la planta hasta entonces, el cual sería finalizado unos años después. En cuatro años se incorporó a la fábrica un sistema de reducción directa para el mineral de hierro (1976), un muelle propio sobre el río Paraná para recibir la materia prima (1978), un cuarto horno eléctrico (1977) y una segunda máquina de colada continua (1978) en la sección acería, y un moderno laminador continuo en la fábrica de tubos (1976).

\footnotetext{
${ }^{4}$ La idea de cargas laborales hace hincapié en los elementos del proceso laboral que interactúan entre sí y con el cuerpo obrero, en relación a una dinámica global del proceso de trabajo que afecta a los trabajadores como colectivo.

5 El desgaste es definido como "la pérdida de capacidad efectiva y/o potencial, biológica y psíquica. O sea, no se refiere a algún proceso particular aislado, sino al conjunto de los procesos biopsíquicos" (Laurell \& Noriega, 1989, p. 76).

${ }^{6}$ A partir de aquí, nos referiremos a la fábrica como Dálmine en pos de simplificar la lectura.
} 
A partir de allí, la producción pasó a estar en línea con la frontera tecnológica internacional, y a superar la media productiva mundial, lo que le permitió a la empresa competir plenamente en el mercado externo en años siguientes y constituirse como una de las más importantes productoras de tubos en el país y en el mundo, en el marco de una reconfiguración de la rama siderúrgica a nivel mundial (Kornblihtt, 2010). Además, al transformarse en una fábrica plenamente integrada (en 1978 lo haría también la otra empresa siderúrgica privada más importante del país, Acindar), comenzó a producir los insumos semielaborados que antes demandaba de la estatal SOMISA y pasó a establecer una relación de competencia directa con el complejo estatal. Esto representó el fin de uno de los pilares en los que se asentaba el Plan Siderúrgico Argentino aprobado en 1947, y marcó el inicio de un período de fuerte concentración en la rama que sería encabezado por los dos grupos empresarios privados más importantes, Acindar y Techint (Azpiazu, Basualdo, \& Kulfas, 2005). ${ }^{7}$

En este período de imponente crecimiento para la planta "madre" del grupo Techint en el país, como contracara, el colectivo obrero de la fábrica sufrió una fuertísima represión, con al menos 22 trabajadores que fueron afectados por los operativos represivos durante 1975 y otros 80 que fueron víctimas de crímenes de lesa humanidad durante el Terrorismo de Estado, con una probada responsabilidad de la empresa en la comisión de esos delitos (AEyT FLACSO, CELS, PVyJ, \& SDH, 2016). El problema de las condiciones de insalubridad en el trabajo se había transformado en uno de los principales motivos de descontento obrero y de disputa con la patronal ${ }^{8}$, particularmente en la sección con mayores niveles de peligrosidad: la acería.

Hacia 1978, aquella sección de la planta tenía una superficie cubierta de $20.500 \mathrm{~m}^{2}$ y constaba de diversas áreas en su interior. En la primera, cuatro hornos eléctricos ubicados en una nave a cinco metros de elevación fundían el hierro esponja a granel y diferentes aditivos para obtener el acero crudo líquido. El proceso de fusión producía, además de altísimas temperaturas a las que los trabajadores estaban expuestos $^{9}$, la mayor contaminación de todo el ciclo productivo, al involucrar productos orgánicos que emanaban gases y humos tóxicos. En segundo término, en el área de la fosa de escorificación, por debajo de los hornos, se trabajaba removiendo las escorias y cenizas provenientes de la fundición, proceso en el cual

\footnotetext{
7 Por cuestiones de extensión, no detallamos aquí toda la serie de "transferencias estatales" que ambos grupos obtuvieron durante la dictadura y la década del ochenta, que fueron también un elemento central para entender su crecimiento durante aquellos años. Al respecto, puede verse Iramain (2013) y Azpiazu, Basualdo y Kulfas (2005).

${ }^{8}$ En este trabajo nos centramos específicamente en las condiciones de insalubridad laboral, dejando para análisis posteriores otras variables relacionadas a la salud de los trabajadores como los llamados "accidentes" laborales.

9 "Y después en los hornos jera terrible!...De frente a la boca del horno, ¡una temperatura! Se ponían delantales y protectores faciales, pero era terrible" recuerda José María Cristaldo, ex trabajador de mantenimiento de la acería y miembro de la comisión interna en los años ochenta. Entrevista del autor, agosto de 2018.
} 
"Si va hablando solo por la calle: trabaja en Dálmine". La salud obrera como campo de disputa en una gran empresa siderúrgica: entre la resistencia de los trabajadores y las prácticas de violencia estatal y empresarial (1974-1978)

los trabajadores se exponían a una abundante cantidad de polvillo irritante para las vías respiratorias.

En el área de lingoteras se producían los lingotes de acero que luego eran llevados a la nave donde se separaban de las placas y se introducían en cuatro piletas de enfriamiento. Posteriormente se los sometía al proceso de rebabado (con la operación de un sopletero y su ayudante), limpieza y posterior marcado para su despacho. Según Cristaldo, el trabajo en las lingoteras era uno de los más duros, vinculándose al ambiente de ruidos, suciedad y calor en el que se desarrollaba la actividad. ${ }^{10}$

Por su parte, en el sector más moderno de colada continua, se producía la palanquilla en cuatro líneas automáticas por las que fluía el acero proveniente de los hornos, el cual progresivamente se enfriaba desde las paredes y se solidificaba. Finalmente, en el área denominada propiamente palanquilla, se cortaba la barra de acero en "tochos" con un soplete, y se realizaba el proceso de selección. Por último, la sección contaba con talleres y equipos de mantenimiento mecánico y eléctrico donde se hacía un trabajo intermitente sobre el equipamiento.

Cabe destacar también que muchas de las operaciones en las áreas de hornos, coladas y lingoteras se realizaban desde puentes grúas elevados a diferentes alturas sobre el nivel del piso, en donde se encontraban los trabajadores en cabinas y pasarelas de circulación, a las que se accedía por escaleras marineras. ${ }^{11}$

En la planta el proceso productivo siempre fue continuo, y los operarios trabajaron en tres turnos rotativos (mañana, tarde y noche), con un régimen laboral de "6x2". Según estudios internacionales, el trabajo en turnos con rotación implica cargas fisiológicas y psíquicas, incluyendo posibles trastornos digestivos como úlceras, tensión nerviosa prolongada, insomnio, fatiga patológica y elevados índices de mortalidad por infarto (Laurell \& Serrano, 1982). Durante la jornada, además, los trabajadores se exponían a numerosos riesgos ambientales, químicos y sonoros, que se constituían como cargas laborales, en "un sector que era el infierno", según rememora Korompay ${ }^{12}$ : el polvillo acumulado en los rieles, los humos y las altas temperaturas en el área de fundición, el ruido en los hornos, la continua tensión nerviosa producto del riesgo de sufrir accidentes en los trabajos en altura en los puentes grúa, los abrasivos utilizados para el corte, las partículas de acero esparcidas por el ambiente, etc. En distintas entrevistas ex trabajadores señalan, además, que los obreros que abandonaban la planta luego de años de servicio

\footnotetext{
10 Ibídem.

${ }^{11}$ El proceso de trabajo fue reconstruido en base al expediente $\mathrm{N}^{\circ}$ 594.46/74. Fondo Documental: Expedientes Generales del Ministerio de Trabajo, en Archivo General de la Nación, Archivo Intermedio.

12 Entrevista del autor a Roberto Korompay, ex abogado asesor de la UOM Campana en los años setenta, diciembre de 2018.
} 
experimentaban problemas de corazón, estómago, oído ${ }^{13}$, sexuales y del sistema nervioso. ${ }^{14}$

\section{La disputa por la insalubridad entre 1974 y 1975: "La época en la que prácticamente mandaban los delegados"}

El ciclo abierto en 1973 con el retorno del peronismo al poder se caracterizó por una profunda conflictividad social y sindical, en el que los reclamos vinculados al mejoramiento de las condiciones de trabajo tuvieron un lugar preponderante. Esto ocurrió en un movimiento de ofensiva de la clase trabajadora que buscaba "explotar las nuevas condiciones políticas abiertas por la victorial electoral para modificar en su beneficio las relaciones de poder en la fábrica y la sociedad" (Pasado y Presente, 1973: 273). Con el antecedente inmediato de la creación de la Dirección Nacional de Higiene y Seguridad en el Trabajo (DNHST) ${ }^{15}$, estos conflictos determinaron algunos avances en la materia, que a nivel general quedaron plasmados en la Ley de Contrato de Trabajo de 1974 y, más específicamente, en la creación del Instituto de Medicina del Trabajo de la UBA en 1973 y el auge en las normas de insalubridad laboral dictadas por el Ministerio de Trabajo: en el período 1973-1975 se dio, de hecho, un pico histórico en estas declaraciones considerando la totalidad de la segunda mitad del siglo XX (San Juan, 2014).

El 14 de noviembre de 1974, a través de la disposición 143/74, la DNHST amplió una resolución tomada previamente por el Ministerio de Trabajo nacional, del cual dependía, disponiendo que la sección acería de la planta Dálmine quedara incluida en su totalidad en lo considerado en el Artículo $6^{\circ}$ del decreto del 11 de marzo de 1930, que consignaba como insalubre a todo "trabajo en cualquier local o sitio en que ocurra habitualmente desprendimiento de polvo o vapores irritantes o tóxicos".16 Como consecuencia de la declaración de insalubridad, todos los trabajadores que se desempeñaban en la sección vieron reducida su jornada laboral a seis horas diarias, con el mismo salario, la imposibilidad de realizar horas extras, y obtuvieron un régimen jubilatorio especial. ${ }^{17}$ La resolución trajo aparejada la creación de un nuevo turno de trabajo en la acería (pasando a ser cuatro turnos de seis horas, en vez de los anteriores tres turnos de ocho horas), en tanto la producción

\footnotetext{
13 "Uno de los principales problemas que tiene Siderca es el ruido. Y la mayor parte de los que han trabajado allí tienen problemas auditivos, tienen hipoacusia bilateral todos”. Ibídem.

14 Entrevista de Alejandro Jasinski a Carlos "el bagre" Elorriaga, ex trabajador del sector de laminación, noviembre de 2014. Entrevista del autor a Rodolfo Amarilla, ex trabajador de la contratista Blois en la sección acería, junio de 2018.

15 Decreto 840/72, reglamentado el 10 de mayo de 1973. Disponible en www.infoleg.gob.ar

16 Ley 11.544, reglamentada el 11/03/1930. Disponible en www.infoleg.gob.ar.

17 De acuerdo al Decreto 4257 de 1968, todo trabajador que se desempeñase en tareas de laminación, acería y fundición en lugares insalubres, poseía el derecho a una jubilación ordinaria con 50 años y 25 de servicios. Disponible en www.infoleg.gob.ar.
} 
"Si va hablando solo por la calle: trabaja en Dálmine". La salud obrera como campo de disputa en una gran empresa siderúrgica: entre la resistencia de los trabajadores y las prácticas de violencia estatal y empresarial (1974-1978)

se realizaba en forma ininterrumpida; y el aumento en el número de trabajadores directos contratados, pasando de 3473 en marzo de 1974 a 4027 un año después. ${ }^{18}$ La decisión del Ministerio de Trabajo generó rápidas y enérgicas reacciones tanto del sector empresario como de distintos funcionarios del Ministerio de Economía.

El directorio de la empresa afirmó que se trataba de una "grave medida" sin antecedentes a nivel de los países más avanzados en materia de higiene laboral, que se sustentaba en "estándares imprecisos" y que se había tomado en forma inmediatamente previa a la puesta en marcha por la empresa de un "moderno y eficiente sistema" para la depuración de humos en la acería. ${ }^{19}$ La empresa también argumentó que la declaración de insalubridad se sumaba a las disposiciones de la Ley de Contrato de Trabajo relativas a los descansos compensatorios por turnos rotativos, a la creación de nuevos puestos de trabajo por "demandas sindicales" y al "ausentismo" en áreas vitales, para explicar la caída en la producción de acero y tubos que la fábrica experimentaba desde 1974. Según los directivos, todos estos últimos factores "considerados globalmente en el ámbito nacional, al reducir la productividad conspiran en definitiva contra el desarrollo del país que requiere precisamente lo contrario: el aumento de eficiencia en sus sectores fabriles". ${ }^{20}$

En el mismo sentido, en una nota escrita durante el mes de noviembre de 1974, el Centro de Industriales Siderúrgicos (principal cámara empresaria del rubro) se dirigió a la Presidenta de la Nación, María Estela Martínez de Perón, para argumentar que la declaración de insalubridad en la sección de acería atentaba contra los conceptos expresados por la propia autoridad nacional acerca de la "necesidad de unificar esfuerzos para mejorar la productividad y aumentar la producción"; y denunció que aquella resolución reducía la productividad en la rama en un $25 \%$ y quitaba a la industria la posibilidad de competir internacionalmente. ${ }^{21}$ Por su parte, en las páginas de la revista Siderurgia, editada por el Instituto Siderúrgico (que nucleaba a las principales empresas del sector), los informes económicos trimestrales entre 1974 y 1975 destacaban regularmente el elevado nivel de "ausentismo" y la baja en la productividad de la mano de obra como preocupaciones empresariales centrales. ${ }^{22}$

La demanda obrera alrededor de las condiciones de insalubridad buscaba ser subordinada por la empresa al tan mentado "problema de la productividad" (Simonassi, 2007), dentro del cual se articulaban críticas generales hacia las "licencias" otorgadas por la nueva Ley de Contrato de Trabajo, la creciente

\footnotetext{
18 Este número no tiene en cuenta a los trabajadores dependientes de contratistas dentro de la planta, que según cálculos estimativos serían alrededor de 2000 para ese entonces. Siderca, Memoria y balance, año 1975, en archivo CISEA-CESPA (FCE-UBA).

19 Ibídem.

20 Siderca, Memoria y Balance, año 1976.

21 Expediente $\mathrm{N}^{\circ}$ 603.041/75. Fondo Documental-Expedientes Generales del Ministerio de Trabajo, en Archivo General de la Nación, Archivo Intermedio.

${ }^{22}$ Revista Siderurgia $N^{\circ}$ 2, 3 y 7. Consultada en Hemeroteca de la Biblioteca Nacional.
} 
"indisciplina" laboral y el aumento de las tasas de "ausentismo" de la mano de obra en las fábricas; en una campaña que abarcaba a otras cámaras empresariales y funcionarios estatales, y poseía carácter nacional desde fines de 1974 (Carminatti, 2018).

El ministro de Economía asumido recientemente, Alfredo Gómez Morales, y otros funcionarios de la cartera se expresaron en una misma línea, poniendo en consideración los efectos desfavorables que las resoluciones de insalubridad poseían sobre la productividad en las industrias de insumos críticos como la siderurgia, afirmando que ese aspecto "está un tanto descuidado y que justifica los mayores esfuerzos" en pos del cumplimiento de las metas de los planes de gobierno. Además, y al igual que el directorio de la empresa, agregaron el "marcado ausentismo" de la mano de obra como factor de preocupación. ${ }^{23}$

A pesar de las distintas quejas, el 24 de abril y el 23 de septiembre de 1975, se promulgaron la resolución 183/75 del Ministerio de Trabajo y el decreto 2620 del Poder Ejecutivo Nacional, donde se desestimaron definitivamente los recursos jerárquicos interpuestos por la firma Dálmine, quedando el conflicto provisoriamente cerrado.

Tanto el ministro de Trabajo como el subdirector de Higiene y Seguridad en el Trabajo en sus resoluciones señalaron que la declaración de insalubridad había obedecido a solicitudes realizadas por la Unión Obrera Metalúrgica (UOM), sindicato al que pertenecía la gran mayoría de trabajadores de la planta. ${ }^{24}$

La seccional Campana se encontraba dirigida desde 1970 por la lista Rosa, integrada por referentes peronistas y encabezada por Ángel Luque, antiguo obrero de la acería presuntamente vinculado para ese entonces al sector de Victorio Calabró dentro de la disputa de la UOM a nivel nacional. La lista Rosa fue reelegida en 1974, esta vez, frente a la Lista Naranja, una escisión encabezada por Luis "el Turco" Dip y presuntamente vinculada a la tendencia de Lorenzo Miguel a nivel nacional. En 1974 también fueron elegidos en la fábrica numerosos delegados y miembros de comisiones internas pertenecientes a distintas corrientes combativas (AEyT FLACSO et al., 2016). El activismo en la fábrica venía creciendo fuertemente, lo cual quedó manifestado en un informe de inteligencia de 1975 que destacaba que la empresa era "la más jaqueada de las empresas de la zona, por el accionar de elementos subversivos". 25

Si bien la dirigencia sindical canalizó la demanda concreta del régimen de insalubridad para la acería, contamos con diversos indicios de que los reclamos por condiciones de trabajo y de salubridad eran sostenidos desde las bases obreras, por delegados y militantes de distintas agrupaciones que actuaban dentro de la fábrica.

\footnotetext{
23 Notas de noviembre y diciembre de 1974 dirigidas al ministro de Trabajo Otero por el Secretario de Estado de Desarrollo Industrial, ingeniero Vasallo, y Alfredo Gómez Morales. Expediente $\mathrm{N}^{\circ}$ $603.041 / 75$.

24 Disposición 143/74 de la DNHST, 14/11/1974.

25 "Principales establecimientos fabriles industriales de la provincia de Buenos Aires que han sufrido estados conflictivos y posible infiltración subversiva". Comisión Provincial por la Memoria-Fondo DIPBA, mesa B, carpeta Varios, legajo 133.
} 


\section{"Si va hablando solo por la calle: trabaja en Dálmine". La salud obrera como campo de disputa en una gran empresa siderúrgica: entre la resistencia de los trabajadores y las prácticas de violencia estatal y empresarial (1974-1978)}

Según legajos de inteligencia, en un volante de la organización PRT-ERP arrojado en la fábrica hacia marzo de 1975 aparecería mencionado que los obreros se venían movilizando desde hacía tiempo por reivindicaciones de salubridad. ${ }^{26}$ Ex trabajadores también señalan la presión que realizaba la comisión interna para exigir, aunque sin éxito, la expansión de la declaración de insalubridad a la sección de tubos ${ }^{27}$, lo que también habría sido impulsado por militantes de organizaciones como el Partido Comunista Revolucionario (PCR). ${ }^{28}$ Otros testimonios resaltan que la demanda "por abajo" en la acería había sido motorizada por José Barreto, militante del Partido Comunista (PC) y miembro de la comisión interna. ${ }^{29}$

En el marco expansivo en el que se encontraba la empresa, tanto el avance de sectores combativos en la fábrica como el fortalecimiento de las representaciones obreras en el lugar de trabajo, habían permitido otra serie de conquistas en este plano hasta 1976: nuevos implementos de seguridad (botines, tapones para los oídos, casco, guantes para cortar el acero, cabinas con aire acondicionado para los gruístas), uniformes para el trabajo en el sector administrativo, la construcción de un comedor dentro del sector de laminación y el mejoramiento en las condiciones de los baños (Peláez, 2018). "Cachi” Theis recuerda ese período afirmando que "prácticamente los que mandaban eran los delegados y Dálmine tuvo que aflojar en muchas cosas". ${ }^{30}$ Por su parte, "el Portugés" Lópes afirma que "conflictos no hubo ninguno. Ni había necesidad de eso porque ellos nos daban todo...Quizás no querían provocar nada. La fábrica en esa altura estaba en auge. Estaban preparando la gran represión, por lo tanto tenían que ser cautelosos, y lo eran". ${ }^{31}$

Por último, como afirmamos, las quejas empresariales se referían a la práctica del "ausentismo laboral" como un fenómeno habitual en la empresa durante aquellos años. Cabe señalar que si bien las fuentes empresarias consultadas no registran estadísticas que sustenten esa afirmación, hay alusiones a esta práctica en algunos testimonios de ex trabajadores:

"Yo me acuerdo de que en esa época se hablaba mucho de que uno de los problemas de la economía era el ausentismo laboral...Entonces vos ibas a las enfermería, por ejemplo, y decías '¿ves que me quebré la uña acá? Me

\footnotetext{
26 "A los compañeros obreros y al pueblo", volante firmado por el PRT-ERP, marzo de 1975. En CPMFondo DIPBA, Mesa DS, Carpeta Varios, Legajo 3155.

27 Entrevista del autor a Juan Manuel “el Portugués” Lópes Goncalves, ex miembro de la comisión interna entre 1974 y 1975, y militante del PRT-ERP. Agosto de 2018. Entrevista del autor a Roberto Muriega, ex trabajador de la sección de laminación y militante del ERP, mayo de 2018.

28 "Por la insalubridad para Dálmine y Cometarsa. Luque nos frena con el cuento de que hay que esperar a que salga el expediente. Hagamos como Siderca que la sacó con lucha". Volante "Por asamblea general", firmado por el PCR el 17/02/1976. En CPM-Fondo DIPPBA, Mesa B, Carpeta 21, Legajo 25.

29 Entrevista a Carlos Elorriaga. Entrevista del autor a Carlos "Cachi" Theis y Carlos Bruni, ex delegados de la sección de laminación y militantes del PC, mayo de 2018.

${ }^{30}$ En "Vino la revancha”, Página 12, 28/11/2011.

31 Entrevista a Lópes Goncalves.
} 
duele un montón. No me puedo poner los guantes'. '¿Cuántos días querés?', te preguntaban. Yo escuchaba toda esa onda del ausentismo...i $\mathrm{i}$ se van a la puta que lo parió!, ¡que laburen ellos!". 32

En síntesis, durante esta primera etapa podemos ver diferentes conquistas de los trabajadores respecto a la "frontera de control" general y en relación a condiciones laborales específicas, enmarcadas en la ampliación de la planta, y en choque con distintas denuncias de la dirección empresarial referidas al avance de los representantes sindicales, la caída de la productividad y el supuesto "ausentismo" de la mano de obra.

\section{“Después del golpe, vino la revancha”: el conflicto durante la dictadura ${ }^{33}$}

Tras el golpe de Estado de 1976 la clase trabajadora se vio duramente afectada por una serie de políticas represivas, económicas y laborales. En este último terreno, se establecieron una serie de normas orientadas a limitar la actividad gremial. Entre otras, se suspendieron las negociaciones paritarias y el derecho a huelga; se prohibió realizar asambleas, reuniones, congresos, elecciones sindicales, y cualquier medida de acción directa como el trabajo a desgano; se eliminaron los fueros gremiales; se disolvió la CGT; y se intervinieron una importante cantidad de grandes sindicatos y federaciones nacionales (Basualdo 2010).

En ese marco, la citada Ley de Contrato de Trabajo fue modificada en mayo de 1976. El nuevo artículo 200 estableció que previo a declarar la insalubridad de un espacio laboral debía intimarse al empleador a adecuar ambientalmente el lugar; y además, introdujo la posibilidad de apelar judicialmente tanto la declaración de insalubridad como su cese. ${ }^{34}$ En forma complementaria, se aprobaron una serie de decretos como el 1895/77 y el 267/79, que excluían la posibilidad de declarar insalubres a tareas laborales específicas. De conjunto, esta política habilitó una revisión de los regímenes de insalubridad aprobados durante el período previo, lo que produjo concretamente que, entre 1976 y 1983, se aprobaran 380 declaraciones de tareas como "normales" frente a apenas 62 casos en los que se declararon nuevas tareas como "insalubres" (San Juan, 2019).

La documentación del Ministerio de Trabajo consultada vuelve a registrar novedades en el caso Dálmine hacia marzo de 1978. Finalizado el grueso de la ampliación de la planta y tras un pedido presentado por la empresa, equipos técnicos de la DNHST se presentaron en dos oportunidades en Campana para realizar revisiones de las innovaciones y verificar los nuevos valores y tiempos de exposición a los contaminantes. Fueron acompañados por el gerente de Relaciones Industriales de la planta, Raúl Pizarro Posse, y por el jefe de Relaciones Laborales,

\footnotetext{
32 Entrevista del autor a Eduardo Pitter, ex supervisor de la planta y militante del PC, mayo de 2018. 33 "Pero después del golpe vino la revancha de la empresa y empezó la represión", concluye "Cachi" Theis. "Vino la revancha", Página 12, 28/11/2011

${ }^{34}$ Ley 20.744/76, disponible en www.infoleg.gob.ar.
} 
"Si va hablando solo por la calle: trabaja en Dálmine". La salud obrera como campo de disputa en una gran empresa siderúrgica: entre la resistencia de los trabajadores y las prácticas de violencia estatal y empresarial (1974-1978)

Federico Wenceslao Mauriño; así como por miembros de la seccional Campana de la UOM y de la comisión interna de la acería.

Los informes oficiales señalaron que la empresa había mejorado las condiciones de contaminación ambiental, exceptuando las que afectaban a tres de las numerosísimas tareas que se realizaban en la sección (rebabado de lingotes, limpieza de escoria, y trabajos en puentes grúa y pasarelas por encima de los hornos), para las cuales se señalaba que la exposición de los trabajadores no excedía la mitad de la jornada laboral y, por lo tanto, sólo se contaría ese tiempo concreto de exposición para el nuevo cálculo (una hora y veinte por cada hora real de trabajo). ${ }^{35}$ En términos generales, para fundamentar el pedido de revisión del régimen de insalubridad, los técnicos citaron en su informe el nuevo "espíritu" de la Ley de Contrato de Trabajo, y específicamente su artículo 200. Además, establecieron que, a pesar de constatarse el alto nivel sonoro existente en la sección de fusión de chatarra, no podía calificarse como tarea insalubre ya que el Poder Ejecutivo no había dictado las normas que permitiesen la vigencia del Decreto 1016/74 de insalubridad por ruidos. ${ }^{36}$

Frente a estos intentos de avanzar sobre las condiciones y derechos laborales existieron diversas dinámicas de acción dentro de la planta durante el período. Estas deben ser visualizadas, con diferentes niveles y matices, en el contexto de aplicación del Terrorismo de Estado a nivel nacional, regional y local, y de una "estrategia industrial disciplinante basada en el terror" dentro de la fábrica, producto de la combinación entre la represión estatal y las denominadas "prácticas empresariales represivas". De acuerdo al informe de Responsabilidad Empresarial en delitos de lesa humanidad, en Dálmine estas últimas incluyeron un amplio abanico de acciones, como el aval a la militarización de la fábrica a partir del golpe de estado, los secuestros de trabajadores dentro de las secciones de la planta, la existencia de infiltrados para realizar tareas de inteligencia, y el envío de telegramas de despido y/o cese de actividades a activistas gremiales que habían sido secuestrados y torturados, entre otras. El directorio de la empresa hacía aportes a la comisaría de Campana y tutelaba el Club Dálmine, donde funcionaron centros clandestinos de detención; además de ser propietaria del hotel Dálmine, que fue utilizado antes del 24 de marzo como espacio de planificación de operaciones del Ejército. El jefe de Relaciones Laborales Federico Mauriño, a quien mencionamos como acompañante de los técnicos de la DNHST en sus visitas a la planta, era encargado de las negociaciones cotidianas con las comisiones internas, y fue identificado por ex trabajadores con un rol destacado en distintos momentos represivos, como cuando contuvo a los obreros para que no tomaran medidas frente al secuestro de uno de

\footnotetext{
35 Expediente N ${ }^{\circ}$ 594.46/74. Fojas 30, 31 y 32.

36 Este decreto obligaba al Ministerio de Trabajo de la Nación a incorporar en los regímenes de insalubridad a las tareas que presentasen niveles sonoros que pusieran en peligro la salud de los trabajadores. Boletín Oficial de la República Argentina №23.012, 10/10/1974.
} 


\section{Pablo Javier Peláez}

ellos desde la planta, o cuando presionó a un delegado que había sido temporalmente secuestrado para que renunciara a su cargo (AEyT FLACSO, CELS, PVyJ, \& SDH, 2016). También fue señalada su colaboración en la elaboración de listas negras de trabajadores junto a integrantes del Área $400^{37}$ desde el hotel Dálmine. ${ }^{38}$ Dentro de la planta, los soldados se dedicaron regularmente durante el período a requisar los cofres y taquillas en los vestuarios de los empleados, y a realizar operativos de control a la entrada y salida de los turnos de producción. Algunos de ellos permanecieron en las plataformas utilizadas por los gruístas para ejercer vigilancia al interior de los galpones de producción, con el objetivo de disciplinar a los trabajadores.

Otra parte central del entramado represivo empresario estuvo constituido por el funcionamiento de una agencia de seguridad privada que actuó como una policía interna de fábrica, contratada por la empresa y organizada desde 1978 por el jefe del área de vigilancia, el suboficial principal retirado de la Fuerza Aérea Roberto P. Nicolini. Además de tener un rol central en la detención y secuestro de trabajadores de la planta, la agencia de seguridad tuvo como principal objetivo la movilización productiva de los trabajadores mediante el disciplinamiento impuesto por procedimientos y requisamientos internos de tipo policial, ante denuncias de jefes, capataces o encargados. Nicolini y sus agentes internos se preocuparon tanto por la militancia gremial y política de los obreros, como por robos de materiales, el "ausentismo" laboral, y por actitudes consideradas "anti-productivas" como la borrachera o el juego clandestino. Como detalló Jasinski en un trabajo reciente (2019), la organización de esta policía interna fue fundamental en el intento de la empresa por retornar a lo que consideraba como el "orden productivo" en la planta. En términos más amplios, ha sido evidenciada la existencia de al menos seis ciclos represivos de acuerdo a la cronología de las víctimas vinculadas a la empresa, tanto trabajadores como familiares (AEyT FLACSO, CELS, PVyJ, \& SDH, 2016). Los primeros dos de ellos, producidos entre marzo y diciembre de 1975 bajo los efectos del operativo denominado "Serpiente Roja del Paraná" y el encuadre brindado por la Ley "antisubversiva" 20.840, tuvieron como objetivos principales a activistas del PRT-ERP y el clasismo en la fábrica. En noviembre de 1975 fue secuestrado también durante cinco días el Secretario General de la UOM Campana, Ángel Luque. ${ }^{39}$ Tras una tercera oleada represiva entre marzo y junio de 1976, se desarrolló entre agosto y diciembre un nuevo ciclo, el cual contó con la llamada "Noche de los Tubos", en la que fueron secuestrados simultáneamente cuatro trabajadores de la fábrica. Un quinto ciclo se dio durante la primera mitad de 1977 y contó con el secuestro de dos trabajadores desde las propias secciones de la fábrica. Por último, una sexta oleada represiva se suscitó hacia fines de 1979, tras la primera huelga desarrollada en la

\footnotetext{
37 El Área 400 fue una de las subzonas en que la dictadura dividió el territorio para operativizar el plan de exterminio. Abarcó Exaltación de la Cruz, Zárate y Campana.

38 Entrevista del autor a Rodolfo Pérez Gianni, ex obrero de laminación y miembro de la comisión interna en la década del ochenta, mayo de 2018.

39 Entrevista a Ángel Luque, realizada por Nuñez, Di Fino y Sadonio. Noviembre de 1998.
} 
"Si va hablando solo por la calle: trabaja en Dálmine". La salud obrera como campo de disputa en una gran empresa siderúrgica: entre la resistencia de los trabajadores y las prácticas de violencia estatal y empresarial (1974-1978)

fábrica durante la dictadura, y contó entre sus víctimas a trabajadores que habían sido partícipes de la misma.

La represión llevada adelante por la alianza militar-empresarial tomó por objeto central a los activistas obreros y a los representantes gremiales de base en la planta de Campana. Entre 1975 y 1980 fueron detenidos, desaparecidos, asesinados, forzados a migrar, y/o secuestrados y liberados, al menos 102 trabajadores del establecimiento, siendo 22 de ellos delegados y 3 integrantes de las comisiones internas. ${ }^{40}$ Las instancias sindicales de base fueron diezmadas de sus miembros más combativos. Hacia 1978, tenemos constancia de que la comisión interna de la sección de laminación, había sido renovada totalmente en su composición respecto al período 1974-1976. Diferentes testimonios señalan que el renovado cuerpo gremial fue puesto a dedo por la empresa bajo la supervisión de militares del Área 400, a la par de que las elecciones de delegados fueron suspendidas (AEyT FLACSO et al., 2016). En relación a la comisión interna de la acería, hacia 1977 fue asesinado José Barreto, a quien indicamos como uno de los integrantes más activos en la lucha por el régimen de insalubridad (HIJOS Escobar-Campana-Zárate en la Red Nacional \& Suteba-Zárate, 2015).

En ese marco, también debe tenerse en cuenta que la UOM nacional fue intervenida por la Junta Militar inmediatamente después del golpe. La seccional Campana no lo fue en forma directa, aunque testimonios resaltan el control al que estuvo sometida su dirección por las autoridades militares del Área 400 asentadas en la zona. Si bien la composición de la Comisión Directiva quedó prácticamente inalterada luego de sucesivos recambios ocurridos entre fines de 1975 y comienzos de 1976, se produjo una modificación de importancia cuando, hacia 1977, presentó su renuncia el Secretario General Luque y asumió como reemplazante Domingo Riedel, quien ya formaba parte de la dirección sindical.

Como respuesta al intento de anular el régimen de insalubridad en la acería, hacia junio de 1978 la UOM nacional decidió enviar un asesor técnico a la planta. En su informe, este corroboró la existencia de "gruesas fallas y omisiones en el dictamen [de la DNHST]...las cuales tornan ineludible la realización de una nueva inspección". Señaló que la empresa había sabido de la inspección de abril de 1978 con varios días de anticipación y que, por lo tanto, había podido contratar en esos días previos de forma excepcional a otra compañía para que regase los sectores, eliminando los polvillos tóxicos acumulados. En el mismo sentido, miembros de la comisión interna y de la seccional Campana de la UOM denunciaron que, el día de la inspección, el número de coladas había sido disminuido intencionalmente, así como que no se había tomado en cuenta el excepcional "factor viento" que había influido favorablemente en las condiciones ambientales. Por ello, afirmaron que la

${ }^{40}$ La cantidad de trabajadores de la fábrica víctimas de la represión sigue actualizándose al día de hoy. 
inspección se había realizado en condiciones anormales de producción, siendo este el principal argumento para impugnarla. En este punto, además, el sindicato reclamó que se revisaran los libros de la firma para verificar la regularidad en la contratación de empresas externas para el servicio de regado y el número de coladas que se registraba habitualmente; es decir, cuáles eran las condiciones normales de producción.

El técnico sindical se encontró además con contaminación acumulada en pasarelas e instalaciones. Señaló que los inspectores oficiales no habían tomado en cuenta el elevadísimo nivel de presión sonora producido por los tornos eléctricos, en el sector de Colada Continua y en las pasarelas de puentes grúas, con una inadecuada protección para el personal ${ }^{41}$; así como la persistente peligrosidad que ocasionaban los residuos de materiales explosivos en la chatarra utilizada. Marcó a su vez la presencia evidente de contaminantes gaseosos en las lingoteras, en el sector de colada continua y en la nave de hornos, además de una ventilación que resultaba insuficiente. Por último, para las tres actividades exceptuadas señaló que los trabajadores, más allá de no estar realizando la actividad laboral concreta, se mantenían en el mismo ambiente y por tanto estaban expuestos a los gases contaminantes durante toda su jornada laboral.

En paralelo, y en términos más generales, el sindicato exigió otro criterio para medir las condiciones laborales, solicitando que representantes de Salud Pública de la Nación efectuaran un chequeo médico a los obreros que trabajaban en dichas secciones riesgosas para evaluar en qué grado eran afectados por los gases nocivos. El efecto determinable sobre la salud del personal de la empresa era, según la organización, el "verdadero indicador de salubridad, independientemente de los valores técnicos ambientales". Se denunciaba, en ese sentido, que ya a la fecha gran parte del personal había contraído enfermedades como neumoconiosis a raíz de las malas condiciones ambientales existentes. ${ }^{42}$ Por último, en un comunicado firmado por la seccional metalúrgica y las comisiones internas algunas semanas después, se afirmaba que la empresa había actuado "de mala fe", y se reclamaba una nueva inspección en la planta en condiciones normales de producción, asentando que se contaba con el apoyo de las autoridades interventoras de la UOM a nivel nacional. ${ }^{43}$ A pesar de las impugnaciones, en una escueta nota fechada algunos días después de la presentación de la UOM, la DNHST descartó de plano los argumentos y desestimó la presentación sindical, principalmente, por no haber presentado mediciones propias de los contaminantes. Finalmente, a través de la resolución M.T. 848 del 8 de agosto de 1978, el ministro de Trabajo Horacio Liendo dejó sin efecto la resolución M.T. N 414/74 y la Disposición DNHST N 143/74, por lo que, al haberse comprobado "que han sido mejoradas las condiciones ambientales de trabajo", las

\footnotetext{
${ }^{41}$ En este punto se afirmaba que la falta de reglamentación del decreto 1016/74 no hacía desaparecer el factor nocivo para los trabajadores, y por tanto, debía ser tomado en cuenta.

42 El informe sindical completo se halla en Expediente 549.547/74, fojas 45 a 54 .

43 Solicitada "A los compañeros metalúrgicos y a la opinión pública en general". La Defensa Popular, $16 / 08 / 1978$.
} 
"Si va hablando solo por la calle: trabaja en Dálmine". La salud obrera como campo de disputa en una gran empresa siderúrgica: entre la resistencia de los trabajadores y las prácticas de violencia estatal y empresarial (1974-1978)

tareas de la sección acería de la empresa volvieron a ser declaradas normales, exceptuando las tres señaladas previamente.

Hacia fines de octubre la comisión directiva de la seccional de la UOM decidió enviar una nueva carta de protesta pero, ya sin perspectiva global de frenar el avance empresario, solicitó al Ministerio expedirse en relación a que la empresa no estaba cumpliendo con el horario reducido en el área de los puentes grúa encima de los hornos. Hasta lograr su objetivo, el sindicato hizo la curiosa advertencia de que se trabajaría "bajo protesta, para colaborar con el normal desenvolvimiento de producción y cooperar con el desarrollo y engrandecimiento del país que es la ambición de todos los trabajadores". ${ }^{4}$ Luego de un nuevo intercambio de notas, la DNHST desestimó este punto del reclamo sindical, reafirmando lo esporádico de las tareas en las pasarelas y los valores medidos en las cabinas de los gruístas, que habían dado por debajo de los máximos permisibles.

En paralelo a este largo intercambio, existieron indicios de movilización y descontento de los trabajadores de base ante la medida adoptada, que se desarrollaron por fuera de los canales sindicales institucionales; incluso del cuerpo de delegados de la sección, el cual estaba "muy apretado" y manifestaba la imposibilidad de llevar adelante medidas de protesta en aquel contexto. ${ }^{45}$ En un expediente de inteligencia de diciembre de 1978 se afirmaba que "se ha tomado conocimiento que existiría malestar entre el personal de la empresa metalúrgica Dálmine-Siderca, por problemas vinculados con el aumento de horas de labor". ${ }^{46}$ Frente a los hechos citados, el periódico del PCR informaba el 18 de agosto de aquel año (día en que se debía retornar a las 8 horas de trabajo) que obreros de la acería habían roto la casilla de la Comisión Interna; mientras que otro turno había abandonado el trabajo cumplidas las seis horas, y varios sectores se habían movilizado al sindicato. ${ }^{47}$ Estas acciones se insertaron dentro de una serie de prácticas de "resistencia subterránea" que los trabajadores desarrollaban desde 1976, como los sabotajes a la producción y el lanzamiento de pedazos de acero a los militares apostados en la fábrica (Peláez, 2018); y presentaron continuidad en el compromiso informal de negarse a realizar horas extras en la acería una vez que fue reimplantada esa posibilidad. 48

Poco tiempo después, movimientos de oposición gremial dentro de la planta retomarían estos indicios de protesta. Hacia 1980, la publicación clandestina "El Tubo", editada por el PC para circular entre los trabajadores de la fábrica, titulaba "Si va hablando sólo por la calle: trabaja en Dálmine", denunciando la continuidad

\footnotetext{
44 Expediente 549.546/74, foja 87.

45 Entrevista a Pérez Gianni. Entrevista del autor a Guillermo Temudio, ex obrero de la acería y miembro de la comisión interna durante la década del ochenta, mayo de 2018.

46 CPM-Fondo DIPPBA, Mesa B, Carpeta 124, Legajo 61.

${ }^{47}$ Nueva Hora, 25/10/1978. En Archivo Nacional de la Memoria.

48 Entrevista a Theis y Bruni.
} 
de las condiciones insalubres de trabajo y poniendo como consigna la de "unirnos y luchar por la jornada de seis horas". ${ }^{49}$ A partir de 1984, la lucha por el retorno al régimen de insalubridad en la acería tendría un nuevo rebrote, llegando a movilizar a las bases obreras e incluso a instancias nacionales de la UOM.

Para cerrar este apartado, cabe analizar cómo se tradujo este cambio en términos económicos para la empresa. Durante 1978 la eliminación del régimen de seis horas en la acería trajo aparejado el fin del cuarto turno de trabajo, la inmediata reducción en la cantidad de obreros empleados, pasando estos de 4087 a 3580, así como la prolongación de la jornada laboral en la sección y la reintroducción de la posibilidad de realizar horas extras. A pesar de la reducción en la cantidad de trabajadores, las toneladas de acero producidas continuaron con el crecimiento experimentado desde 1976, dando un salto anual del 15\%.50 Esto puede explicarse por un aumento de la productividad de la mano de obra ocasionado por la definitiva puesta en marcha de las nuevas instalaciones, pero también por una intensificación del trabajo en la planta. ${ }^{51}$

Operó en este sentido, además del disciplinamiento general de los trabajadores vía represión, la eliminación durante el período del denominado "relevo de puestos", que consistía en un grupo de empleados que permanecían en la planta para el reemplazo de ausentes, y la implantación del "servicio ininterrumpible", por lo que si faltaba un trabajador, el compañero del turno anterior debía quedarse y realizar hasta una doble jornada laboral en el puesto. ${ }^{52}$ De la misma manera, la empresa habría logrado una virtual extinción del problema del "ausentismo" de la mano de obra, el cual dejó de aparecer mencionado tanto en las publicaciones como en sus balances. Al respecto, Pitter recuerda que "dan el golpe y a los dos días a todos los que estaban con parte de enfermo y ausentes les llegó una carta telegrama o que se incorporen a trabajar o que se consideren despedidos. Esa coyuntura fue muy concreta en ese sentido". 53

Los avances descriptos, enmarcados en la finalización de la ampliación de la planta ocurrida hacia 1978, permitieron que la patronal comience a imponer tres de sus grandes objetivos para el mediano plazo: la reducción de la mano de obra empleada, el aumento de la productividad y la intensificación del trabajo en la planta.

\section{A modo de cierre}

El análisis de este proceso de conflictividad suscitado en una gran empresa industrial en torno a la salud de los trabajadores durante un período de cuatro años, aunque puede parecer un objeto de estudio específico y delimitado, sintetiza, como

\footnotetext{
${ }^{49}$ El Tubo, N 1 , abril de 1980. En CPM-Fondo DIPPBA, Mesa DS, Carpeta varios, Legajo 17365.

${ }^{50}$ Siderca, Memoria y Balance, años 1976, 1977, 1978 y 1979.

${ }^{51}$ Entendemos la intensificación del trabajo como "un mayor gasto de trabajo en el mismo tiempo, una tensión acrecentada de la fuerza de trabajo, un taponamiento más denso de los poros que se producen en el tiempo de trabajo" (Marx, 2002, p. 499).

52 Entrevista a Pérez Gianni.

${ }^{53}$ Entrevista a Eduardo Pitter.
} 
"Si va hablando solo por la calle: trabaja en Dálmine". La salud obrera como campo de disputa en una gran empresa siderúrgica: entre la resistencia de los trabajadores y las prácticas de violencia estatal y empresarial (1974-1978)

explica Laurell, "elementos centrales de la contradicción entre capital y trabajo, por cuanto plantea, en su límite extremo, la ganancia del uno como la muerte del otro" (Laurell \& Noriega, 1989, p. 195).

En este sentido, entendemos que, en el contexto de la segunda etapa de la ISI, la conflictividad por la salud obrera fue fundamental dentro de una contienda más general por la definición de la "frontera de control" en las condiciones de producción dentro de las fábricas. Presentada por funcionarios estatales y cámaras empresariales desde la década del cincuenta como el "problema de la productividad", esta línea de disputa no hizo sino profundizarse con el alza en la lucha de clases y la radicalización de una parte de los trabajadores de base en las industrias dinámicas hacia principios de los años setenta.

Con los importantes antecedentes represivos durante 1975, el inicio de la última dictadura en Argentina produjo un punto de inflexión en esta dinámica. Se viabilizó abiertamente entonces el intento del capital por disciplinar a los trabajadores y barrer los fundamentos del poder obrero consolidado en las fábricas durante la segunda mitad del siglo XX, a partir de una agresiva transformación económica, una brutal represión y una importante modificación de las relaciones laborales (Basualdo \& Jasinski, 2016). Para comprender la extrema represión de la que fue objeto el colectivo obrero en la empresa Dálmine por parte de la alianza militarempresarial durante el período, es imprescindible tener en cuenta esta disputa.

En este sentido, hemos visto que, más que la modificación de las condiciones laborales para garantizar la efectiva salud de los trabajadores, la represión estatal y las formas de violencia empresarial aplicadas para hacer retroceder de manera sustancial a la organización gremial en el lugar de trabajo, fueron la clave para que la empresa logre la anulación de casi todo el régimen de insalubridad en la planta hacia 1978. El detallado informe que el sindicato presentó, con impugnaciones graves al estudio técnico realizado previamente por los funcionarios estatales y con propuestas para realizar un análisis con criterios diferentes, fue desechado con pocos fundamentos. Se trató de un problema que, basado en elementos objetivos y técnicos, se definió en un sentido estrictamente político, de correlación de fuerzas:

"La experiencia acumulada muestra, pues, que la fuerza y organización social de los trabajadores es un elemento clave en la determinación del grado de desgaste que sufren en el proceso laboral; que la salud obrera está ubicada en el campo de la lucha de clases y no en un terreno imaginario de neutralidad científica. En términos de la sociedad, la cuestión que está planteada es qué homicidios está dispuesta a considerar como socialmente legítimos. Y la respuesta difiere de una a otra clase" (Laurell \& Noriega, 1989, p. 201).

También hemos visto que los trabajadores de base mostraron indicios de descontento con el retroceso en sus condiciones laborales, desarrollando diferentes 
formas de "resistencia molecular" y "subterránea" (Falcón, 1996; Pozzi, 1988) por fuera de los canales sindicales. Esas prácticas, si bien no alcanzaron dimensiones de magnitud para frenar el avance patronal en el lugar de trabajo, se mostraron como parte de un "discurso oculto", de una gama de prácticas de la "infrapolítica" (Scott, 1990), que resultaría clave para la rehabilitación de la conflictividad abierta y las demandas en este eje durante años posteriores.

El recorrido también nos permite algunas reflexiones en torno a las discusiones historiográficas evidenciadas inicialmente. Particularmente, señalamos que la conflictividad respecto a condiciones de trabajo y salud puede ser vista en una periodización más extendida que la propuesta por autores como Jelin (1977). Evidenciamos en este sentido la potencialidad de pensar en cronologías más amplias, integrando dos períodos (1973-76 y 1976-78) que generalmente tienden a verse por separado, contemplando como unidad contradictoria momentos de flujo y reflujo del accionar obrero.

Por otra parte, observamos que la demanda en relación a la insalubridad laboral no fue impulsada específicamente por una organización político-sindical, como propuso en su estudio Lissandrello (2017), sino que recorrió en forma transversal a distintas corrientes del activismo en la fábrica y a diferentes niveles de la organización gremial, desde los delegados de base hasta parte de la dirigencia sindical. En el mismo sentido, y retomando lo expresado por autores como Basualdo y Lorenz (2012), evaluamos la necesidad de conceptualizar esta línea de conflictividad en relación a una serie de determinantes más amplios, de carácter estructural. Estos hicieron que Dálmine, como parte de una rama industrial particularmente dinámica del período, contara con un proceso de trabajo intensivo, que implicaba un fuerte desgaste del cuerpo obrero y la exposición a diferentes cargas laborales dañinas para la salud. En este caso, el activismo político y sindical logró canalizar demandas que encontraron anclaje en esas condiciones de producción.

En tercer lugar, evidenciamos que la disputa no puede ser encorsetada en el intento por obtener mejoras salariales indirectas, como plantearon Torre (1983) y Schneider (2017). A través de distintas fuentes, pudimos ver que en Dálmine el reclamo fue sentido y expresado por los trabajadores de base, relacionándose con una experiencia diaria en el lugar de trabajo, y con la búsqueda de reducir la exposición a intensas cargas laborales. Por su parte, creemos que este tipo de demandas presenta una potencialidad política más profunda que la mera reivindicación salarial, al poner en discusión aspectos del proceso productivo y establecer un punto de partida posible para la reapropiación de su control por los trabajadores, como ocurrió en casos paradigmáticos como el de los astilleros Astarsa (Lorenz, 2013). Si bien en Dálmine la reivindicación no tuvo como fin en sí mismo el control del proceso productivo por los trabajadores y terminó ciñéndose al tipo de demanda respaldada por la dirigencia sindical metalúrgica y el gobierno peronista, la obtención del régimen de insalubridad representó un avance para los obreros en términos de la "frontera de control" dentro de la fábrica, que se vio 
"Si va hablando solo por la calle: trabaja en Dálmine". La salud obrera como campo de disputa en una gran empresa siderúrgica: entre la resistencia de los trabajadores y las prácticas de violencia estatal y empresarial (1974-1978)

potenciada por otras conquistas en las condiciones laborales más generales ocurridas durante el período. ${ }^{54}$

Por último, el recorrido nos deja planteada una línea de trabajo amplia a futuro. Esta gira en torno a la hipótesis de que para entender el salto que la empresa pudo dar en su inserción exportadora y su competitividad a nivel mundial durante el período, debe tomarse en cuenta no solo el crecimiento de la productividad de la mano de obra producto de las novedosas instalaciones en la planta, y las "transferencias estatales"; sino también los avances que la patronal logró durante la etapa dictatorial en el disciplinamiento de la mano de obra, la intensificación del trabajo y en la definición de nuevas condiciones de producción regresivas para los trabajadores, a través de la profundización de una formidable serie de prácticas de violencia empresarial. Con este piso, la empresa lograría avanzar durante la década del ochenta hacia una segunda fase de reconfiguración laboral y productiva, basada esta vez en la flexibilización de las condiciones de trabajo y la polivalencia de la mano de obra, que le permitirían pasar a ubicarse definitivamente como un gran grupo empresarial del rubro a nivel internacional.

\section{Bibliografía}

Abós, A. (1984). Las organizaciones sindicales y el poder militar, 1976-1983. En Biblioteca Política argentina: Vol. 60. Buenos Aires: Centro Editor de América Latina.

AEyT FLACSO, CELS, PVyJ, \& SDH. (2016). Responsabilidad empresarial en delitos de lesa humanidad. Represión a trabajadores durante el terrorismo de Estado. Posadas: Editorial Universitaria de la Universidad Nacional de Misiones.

Antunes, R. (2013). Los sentidos del trabajo: Ensayo sobre la afirmación y la negación del trabajo. Buenos Aires: Herramienta Ed.

Azpiazu, D., Basualdo, E., \& Kulfas, M. (2005). La industria siderúrgica en Argentina y Brasil durante las últimas décadas. FETIA-CTA.

Barragán, I. (2016). ¿Quién construye la Nación? Obreros y militares en el Astillero Río Santiago. Procesos de trabajo, violencia y represión (1969-1979) (Tesis doctoral inédita). Facultad de Filosofía y Letras de la Universidad de Buenos Aires.

\footnotetext{
${ }^{54}$ A futuro, buscaremos indagar en fuentes que nos permitan una caracterización más precisa de las distintas estrategias gremiales puestas en práctica durante el período, en relación al equilibrio y la contradicción entre las reivindicaciones económicas y las reivindicaciones de control; retomando planteos presentes en trabajos como el de Soul (2014).
} 
Basualdo, V. (2010). La clase trabajadora durante la última dictadura militar argentina. Dossier Educación y Memoria. Memoria en las aulas. Comisión Provincial por la Memoria, 13.

Basualdo, V. (2011). La organización sindical de base en Acindar Villa Constitución en la segunda ISI: apuntes para la comprensión de sus particularidades y su significación histórica. En V. Basualdo (Ed.), La clase trabajadora argentina en el siglo XX: experiencias de lucha y organización (pp. 234-278). Buenos Aires: Cara o Ceca.

Basualdo, V. (2018). Militancia y organización obrera de base durante la primera mitad de los años setenta: una aproximación desde la historia oral al caso de Alpargatas en Florencio Varela. En K. Grammático, M. Marini, \& W. Wechsler (Eds.), Historia reciente, género y clase trabajadora. Buenos Aires: Imago Mundi.

Basualdo, V. (2018). The Argentine Dictatorship and Labor (1976-1983): A Historiographical Essay. International Labor and Working-Class History, 93, 8-26. Basualdo, V., \& Jasinski, A. (2016). La represión a los trabajadores y el movimiento sindical. En G. Águila, S. Garaño, \& P. Scatizza (Eds.), Represión estatal y violencia paraestatal en la historia reciente argentina: nuevos abordajes a 40 años del golpe de estado. La Plata: FAHCE-UNLP.

Basualdo, V., \& Lorenz, F. (2012). Los trabajadores industriales argentinos en la primera mitad de la década del '70: propuestas para una agenda de investigación a partir del análisis comparativo de casos. Páginas. Revista Digital de la Escuela de Historia (UNR), (6).

Bieber, L. (1983). El movimiento obrero argentino a partir de 1976. Observaciones al trabajo de Francisco Delich. En P. Waldmann \& E. Garzón Valdés, El poder militar en la Argentina, 1976-1981. Buenos Aires: Galerna.

Burawoy, M. (2014). Una nueva aproximación a Manufacturing consent. Revista de Trabajo, Nueva Época, 10.

Carminatti, A. (2010). Conflictividad obrera durante la última dictadura militar en Rosario y el "Cordón Norte del Gran Rosario". El otoño caliente de junio de 1977. En D. Dicósimo \& S. Simonassi (Eds.), Trabajadores y empresarios en la Argentina del siglo XX. Buenos Aires: Prohistoria.

Carminatti, A. (2018). Del “ausentismo" a la "subversión industrial”. La construcción discursiva de un enemigo (1974-1976). En S. Simonassi \& D. Dicósimo, Trabajadores y sindicatos en Latinoamérica (pp. 99-112). Buenos Aires: Imago Mundi. 
"Si va hablando solo por la calle: trabaja en Dálmine". La salud obrera como campo de disputa en una gran empresa siderúrgica: entre la resistencia de los trabajadores y las prácticas de violencia estatal y empresarial (1974-1978)

Darlington, R. (2014). The role of Trade Unions in Building Resistance: Theoretical, Historical and Comparative Perspectives. En M. Atzeni, Workers and Labour in Globalised Capitalism. Contemporary Themes and Theoretical Issues. London: Palgrave Macmillan.

De Gaudemar, J. P. (1991). El Orden y la Producción. Nacimiento y formas de la disciplina de fábrica. Madrid: Trotta.

Delich, F. (1982). "Después del diluvio, la clase obrera”. En A. Rouquié (comp.), Argentina, hoy. México: Siglo XXI.

Delich, F. (1983). Desmovilización social, reestructuración obrera y cambio sindical. En P. Waldmann \& E. Garzón Valdés, El poder militar en la Argentina, 1976-1981. Buenos Aires: Galerna.

Dicósimo, D. (2016). Los trabajadores argentinos y la última dictadura: oposición, desobediencia y consentimiento. Buenos Aires: Editorial UNICEN.

Edwards, P. (1986). El conflicto en el trabajo. Un análisis materialista de las relaciones laborales en la empresa. Madrid: Ministerio de Trabajo y Seguridad Social.

Esponda, M. A. (2012). Trabajo y salud en los años de la reestructuración productiva. El caso de los trabajadores de la ex Propulsora Siderúrgica, Ensenada, Buenos Aires. Cadernos de Campo, Sao Paulo (21), 81-98.

Falcón, R. (1996). La resistencia obrera a la dictadura militar. En H. Quiroga, C. Tcach Abad, \& R. Sidicaro (Eds.), A veinte años del golpe: con memoria democrática. Rosario: Homo Sapiens Ediciones.

Fernández, A. (1985). Las prácticas sociales del sindicalismo, 1976-1982. Buenos Aires: Centro Editor de América Latina.

Gallitelli, B. Y Thompson, A. (1990) La política laboral en la Argentina del "Proceso". En G. Fallabella y M. Barrera (comps.), Sindicatos bajo regímenes militares. Argentina, Brasil, Chile. Santiago de Chile: CES-Naciones Unidas.

Ghigliani, P. (2012). La resistencia de Luz y Fuerza a las políticas de la dictadura: los conflictos de 1976 y 1977. Historia Regional, Sección Historia, 30, 51-71. 
Gilly, A. (1985, marzo). La mano rebelde del trabajo. Cuadernos del Sur, 1.

Gilly, A. (1986, mayo). La anomalía argentina. Cuadernos del Sur, 4.

HIJOS Escobar-Campana-Zárate en la Red Nacional \& Suteba-Zárate (2015). Informe Área 400. Represión en las ciudades de Campana, Zárate y Exaltación de la Cruz desde los años 1973 a 1980.

Hyman, R. (1978). El marxismo y la sociología del sindicalismo. México: Era.

Hyman, R. (1981). Relaciones industriales: una introducción marxista. Madrid: H. Blume.

Iramain, L. (2013). Los ganadores de un sector en crisis. El desempeño económico de las grandes empresas siderúrgicas, 1976-1981. H-industri@. Revista de historia de la industria, los servicios y las empresas en América Latina, Año 7, № 12.

Izaguirre, I. (2009). Las luchas obreras y el genocidio en la Argentina. En I. Izaguirre (Ed.), Lucha de clases, guerra civil y genocidio en la Argentina. 1973-1983. Antecedentes. Desarrollo. Complicidades. Buenos Aires: Eudeba.

Jasinski, A. (2019) Para hablar sobre violencia empresarial. Terrorismo estatal y empresas en Argentina: un diálogo con Brasil. En Alejandro Schneider (Comp.), Los ochenta en América Latina. Más allá de "transiciones" y de "pérdidas". Buenos Aires: Imago Mundi.

Jelin, E. (1977). Conflictos laborales en la Argentina. 1973-1976. Estudios Sociales, 9.

Kornblihtt, J. (2010). ¿Una excepción a la regla? Siderurgia competitiva en un país agrario, las bases históricas de la expansión internacional de Siderca desde Argentina (1954-1989). CLADHE II / AMHE IV. Centro Cultural Universitario Tlatelolco (CCUT), Ciudad de México, México.

Laurell, A. C. (1975). Ciencia y experiencia obrera: La lucha por la salud en Italia. Medicine, 9 (7), 351-63.

Laurell, A. C. (1982). La salud-enfermedad como proceso social. Revista latinoamericana de Salud, 2 (1), 7-25.

Laurell, A. C., \& Serrano, M. (1982). Crisis y salud en América Latina. Cuadernos Políticos, 33, 32-45.

Laurell, A. C., \& Noriega, M. (1989). La salud en la fábrica. Estudio sobre la industria 
"Si va hablando solo por la calle: trabaja en Dálmine". La salud obrera como campo de disputa en una gran empresa siderúrgica: entre la resistencia de los trabajadores y las prácticas de violencia estatal y empresarial (1974-1978)

siderúrgica en México. México, D.F: Era.

Lissandrello, G. (2017). La construcción sindical montonera en los tiempos del Pacto Social: la articulación entre la Juventud Trabajadora Peronista (JTP) y el Instituto de Medicina del Trabajo (IMT). 1973-1974. En B. Rupar, A. Costilla, \& G. Galafassi (comps.), Dirán “Hubo gigantes aquí”. Izquierda, peronismo y clase obrera en los '60 y'70. (pp. 139-160). Buenos Aires: Extramuros.

Löbbe, H. (2006). La guerrilla fabril: clase obrera e izquierda en la Coordinadora Interfabril de Zona Norte (1975-1976). Buenos Aires: Ediciones RyR.

Lorenz, F. (2007). Los zapatos de Carlito: una historia de los trabajadores navales de Tigre en la década del setenta. Buenos Aires: Grupo Editorial Norma.

Lorenz, F. (2013). Algo parecido a la felicidad: una historia de la lucha de la clase trabajadora durante la década del setenta : 1973-1978. Buenos Aires: Edhasa.

Marx, K. (2002). El capital: Crítica de la economía política. Tomo I, Volumen I. México: Siglo XXI Editores.

Pasado y Presente. (1973, diciembre). El significado de las luchas obreras actuales. Pasado y Presente, 2/3, 271-282.

Pegoraro, J. (1979, agosto). Los conflictos laborales, 1973-1976. Cuadernos de Marcha, 2, 89-98.

Peláez, P. (2017, agosto). Hacia una caracterización del conflicto capital-trabajo en los años '70: apuntes e hipótesis desde una lectura 'obrerista'. Ponencia presentada en XVI Jornadas Interescuelas/Departamentos de Historia, Universidad Nacional de Mar del Plata.

Peláez, P. (2018, octubre). 'Acá mandamos los de ropa azul'. Líneas de conflictividad y reorganización gremial en una gran empresa siderúrgica entre 1974 y 1983. Ponencia presentada en XI Seminario Internacional Políticas de la Memoria, Centro Cultural Haroldo Conti.

Pozzi, P. (1988). Oposición obrera a la dictadura (1976-1982). Buenos Aires: Contrapunto.

Ríos, M. (2017). Metalúrgica INSUD: lucha obrera fabril y sindicalismo de base. La Matanza, marzo de 1974. En D. Dawyd (Ed.), Si trabajo me matan. Las huelgas 
metalúrgicas en La Matanza en 1974: INSUD, Martín Amato y Santa Rosa. Buenos Aires: Universidad Nacional de La Matanza.

San Juan, C. (2014). Control obrero de las condiciones y medio ambiente de trabajo, mimeo. Disponible en https://www.academia.edu/19608085/Libro Control Obrero abril 2014

San Juan, C. (2019). La salud y seguridad de los trabajadores en tiempos de dictadura, mimeo.

Schmucler, H., Gordillo, M., \& Malecki, J. S. (Eds.). (2009). El obrerismo de Pasado y presente: Documentos para un dossier, no publicado, sobre Sitrac-Sitram. La Plata, Buenos Aires, Argentina: Ediciones Al Margen.

Schneider, A. (2015). Cuando se hizo tronar el escarmiento. La política laboral de Juan D. Perón para disciplinar el movimiento obrero. En P. Ghigliani \& A. Schneider (Eds.), Clase obrera, sindicatos y Estado. Argentina (1955-2010) (pp. 107-127). Buenos Aires: Imago Mundi.

Schneider, A. (2017). "Ni Mongo Aurelio puede gobernar sin apoyo sindical..." Protesta obrera y respuesta de la dirigencia gremial durante el primer semestre del gobierno de Isabel Perón. En B. Rupar, A. Costilla, \& G. Galafassi (Eds.), Dirán "Hubo gigantes aquí". Izquierda, peronismo y clase obrera en los '60 y '70. (pp. 161-180). Buenos Aires: Extramuros.

Simonassi, S. (2007). "A trabajar y muzzarella". Prácticas y políticas de disciplinamiento laboral en la industria metalúrgica de Rosario, 1974-1983", en Revista Historia Regional, N²5, Villa Constitución.

Soul, M. J. (2014). Somiseros: La configuración y el devenir de un grupo obrero desde una perspectiva antropológica. Rosario, Argentina: Prohistoria Ediciones.

Scott, J. (1990). Los dominados y el arte de la resistencia. México: Era.

Torre, J. C. (1983). Los sindicatos en el gobierno, 1973-1976. Buenos Aires: Centro Editor de América Latina.

Venero, F. (2015). Trabajadores y dictadura. Un balance crítico sobre la producción historiográfica. En A. Schneider \& P. Ghigliani (Eds.), Clase obrera, sindicatos y Estado. Argentina (1955-2010) (pp. 129-147). Buenos Aires: Imago Mundi.

Werner, R., \& Aguirre, F. (2009). Insurgencia obrera en la Argentina, 1969-1976: clasismo, coordinadoras interfabriles y estrategias de la izquierda. Buenos Aires: Ediciones IPS. 
"Si va hablando solo por la calle: trabaja en Dálmine". La salud obrera como campo de disputa en una gran empresa siderúrgica: entre la resistencia de los trabajadores y las prácticas de violencia estatal y empresarial (1974-1978)

Zorzoli, L. (2015). La normativa sindical entre la dictadura y el alfonsinismo, propuesta de sistematización. En A. Schneider \& P. Ghigliani (Eds.), Clase obrera, sindicatos y Estado. Argentina (1955-2010). (pp. 149-171). Buenos Aires: Imago Mundi.

Zorzoli, L. (2016). Operativo Ginebra. La dirigencia sindical ante la instalación internacional de la dictadura militar (1976). Archivos de historia del movimiento obrero y la izquierda., 8, 13-32.

Zorzoli, L. (2018). Las intervenciones a organizaciones sindicales durante la última dictadura militar argentina: un estudio cuantitativo, en Desarrollo Económico. Buenos Aires; vol. 57 pp. 487 - 510.

Recibido: $12 / 07 / 2019$

Evaluado: 20/08/2019

Versión Final: 10/09/2019 